\title{
SYNTHESIS OF BIO-NANOMAGNETITE AND ITS OPTIMIZED CONDITIONS FOR PHTHALATE ABSORBTION
}

\author{
F. Hosseini ${ }^{*}{ }^{1}$, Z. Eshaghi ${ }^{2}$ \\ ${ }^{1}$ MS Student, Department of Chemistry, Payame Noor University, 91735-433 Mashhad, Iran \\ 2 Full Professor, Department of Chemistry, Payame Noor University, 19395-4697 Tehran, Iran
}

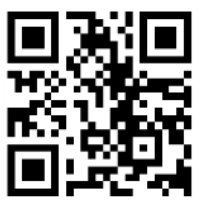

DOI: https://doi.org/10.29121/IJOEST.v4.i3.2020.76

Article Type: Research Article

Article Citation: F. Hosseini, and Z. Eshaghi. (2020). SYNTHESIS OF BIO-NANOMAGNETITE AND ITS OPTIMIZED CONDITIONS FOR PHTHALATE ABSORBTION. International Journal of Engineering Science Technologies, 4(3), 1-12. https://doi.org/10.29121/IJOEST.v 4.i3.2020.76

Received Date: 04 April 2020

Accepted Date: 30 April 2020

Keywords:

Bio-Nanoparticles

PBA

PBAT

Nanomagnetite

UV-Vis

Phthalates

\section{ABSTRACT}

Motivation/Background: Magnetic polymeric nanoparticles have vast range of applications in various fields. Coating or encapsulating of magnetic particles with polymers is one of the most useful methods of modifying magnetic nanoparticles. As these coated particles have magnetic characteristics, they can be easily collected with a single magnet instead of burdensome and time-consuming methods such as centrifugation.

Method: In this work, nano magnetite particles were synthesized using coprecipitation method and then they were firstly coated with a single biodegradable co-polymer, i.e. poly(butylene adipate-co-terephthalate) (PBAT), and secondly with a mixture of two biodegradable polymers of PBAT and poly(butylene adipate) (PBA).

Results: Fourier Transform Infrared (FTIR) spectrum of these two bionanoparticles showed their characteristics. They were also used to absorb dibutyle phthalate and dioctyle phthalate from aqueous solutions. UV-Vis was used to characterize optimization of particle mass, time and stirring speed during absorption. XRD spectrum was also taken. Volume, time and stirring speed of desorption were also optimized. In addition, calibration was performed, and the isotherm was plotted for two particles.

Conclusions: According to XRD spectrum, particles were in nano range. They had acceptable biodegradation characteristics. They also were efficient in absorbing and desorbing phthalates and were collected easily through magnet.

\section{INTRODUCTION}

Magnetic materials have various applications in different fields such as magnetic storage media [1], Ferro fluids [2], magnetic resonance imaging (MRI) [3], magnetically guided drug delivery [4] magnetic bio-separation [5], heavy metal removal [6], and cancer therapy [7]. They have been used extensively as they have various properties such as magnetism, catalytic features, conduction and biological acceptance [8]. The production method of nanomagnetite particles can be divided generally into two approaches, physical and chemical methods [9]. One example of physical method is evaporating particulate materials in tube furnace containing ultra-pure nitrogen. However, physical methods suffer from poor size and shape. Chemical methods are simpler and more efficient [10]. Various methods such as reverse micelle, copolymer gels, solvothermal reduction, ion exchange resin and co-precipitation are used 
Synthesis of Bio-Nanomagnetite and Its Optimized Conditions for Phthalate Absorption

[11]. Among these, co-precipitation method is probably the most promising one due to its simplicity, productivity, and low cost in the production process [9].

Surface modification and functionalization of magnetite nanoparticles are performed using coating materials. Easy aggregation and instability of bare nanomagnetite particles in aqueous solution, high surface energy, and susceptibility to oxidation lead to the stabilization of iron oxide particles by surface modification so that they can be used in various potential fields [12] [13]. Surface modification is easily performed through the creation of few atomic layers of organic (polymer) or inorganic (metal or oxide) surfaces [14][15]. This coating can be comprised of several materials such as organic, inorganic, polymeric and non-polymeric ones [16]. For example, Lee and Harris (2006) attached oleic acid to the surface of magnetite by ozonolysis and made it more lypophilic [17]. Yantasee et al. (2007) used surface modification of dimercaptosuccinic acid (DMAS) to synthesize superparamagnetic iron oxide $\left(\mathrm{Fe}_{3} \mathrm{O}_{4}\right)$ and employed them as a useful sorbent material for toxic soft metals such as $\mathrm{Hg}(\mathrm{II}), \mathrm{Ag}(\mathrm{I}), \mathrm{Pb}(\mathrm{II}), \mathrm{Cd}(\mathrm{II})$ and $\mathrm{Tl}(\mathrm{I})$ ions which actively bind to the DMSA ligand and for As(III) which binds to the iron oxide lattice [18]. Zhang et al. (2011) reported that the application of starch as a stabilizer in preparation of the $\mathrm{Fe}_{3} \mathrm{O}_{4}$ particles can effectively reduce particle aggregation and lead to the formation of more effective adsorbing sites on magnetite particle surfaces [19]. Another investigation [20] described the formation of magnetite in the presence of $1 \mathrm{wt} . \%$ poly(vinyl alcohol). Low dispersed chitosan-bound $\mathrm{Fe}_{3} \mathrm{O}_{4}$ nanoparticles were utilized as a unique nano-adsorbent for the removal of heavy metal ions [21].

Rapid industrialization and urbanization have created various pollutants particularly those entering aquatic systems so development of efficient and cost-effective methods for environmental treatment is critical. Nanomagnetites are ideal candidates for pollutant removal and toxicity mitigation due to extremely small size, high ratio of surface area to volume and more importantly the magnetism [22]. Methods of pollutants adsorption to the surface of these nanoparticles include physical adsorption, ion-exchange, chemical bonding, hydrogen bonds, and van der Wall forces. For example, composite of $\mathrm{Fe}_{3} \mathrm{O}_{4} / \mathrm{ZrO}_{2} /$ chitosan was synthesized and employed for the removal of amaranth and tartazine dyes [23].

Phthalates have been used extensively as plastifying agent to make polyvinyl chloride supple and flexible. They exist in the environment, food samples, medical devices, perfume and cosmetics [24]. Phthalates tend to bioaccumulate in the environment and they are poorly degradable and toxic [25]; so monitoring phthalates is of significant importance due to their wide use and toxicity [26]. In this work, it has been tried to absorb phthalate from aqueous solution by nanomagnetite particles. Then, absorbance and desorption conditions were optimized.

\section{MATERIALS AND METHODS}

\subsection{MATERIALS}

1,4-butanediol (BD; Merck, 99\%), adipic acid (ADA; Merck, 99\%), terephthalic acid (TA; Merck, 98\%), and titanium (IV)tetra-n-butyl orthotitanate (TBT; Merck, 98\%) were purchased and used for synthesizing polymers. $\mathrm{FeCl}_{3} \cdot 6 \mathrm{H}_{2} \mathrm{O}()$ and $\mathrm{FeCl}_{2} \cdot 4 \mathrm{H}_{2} \mathrm{O}()$ along with $\mathrm{NaOH} \mathrm{()}$ and $\mathrm{HCl}$ (Merck, 37\%) were used to synthesize the nanoparticle. Dibutyl phthalate (Merck, > 99\%) and dioctyl phthalate (Merck, 98\%) were purchased and used as received. All solvents were at analytical degree.

\subsection{METHODS}

Polymers and nanoparticles were synthesized according to our previous work [27]. So, a brief description is given. Preparing solutions and optimization methods will explain next. 


\subsubsection{POLYMER SYNTHESIS}

PBA was synthesized through two-stage melt polycondensation (first esterification and then polycondensation) using BD and ADA with TBT as catalyst (molar ratio of 1:1:0.1, respectively). Nitrogen atmosphere and vigorous stirring were applied. The reaction is as follows:

1) $\mathrm{C}_{4} \mathrm{H}_{8}(\mathrm{OH})_{2}+\mathrm{C}_{4} \mathrm{H}_{8}(\mathrm{COOH})_{2} \underset{\mathrm{N}_{2}, 180^{\circ} \mathrm{C}}{\stackrel{\mathrm{Ti}(\mathrm{OBu})_{4}}{\longrightarrow}}$
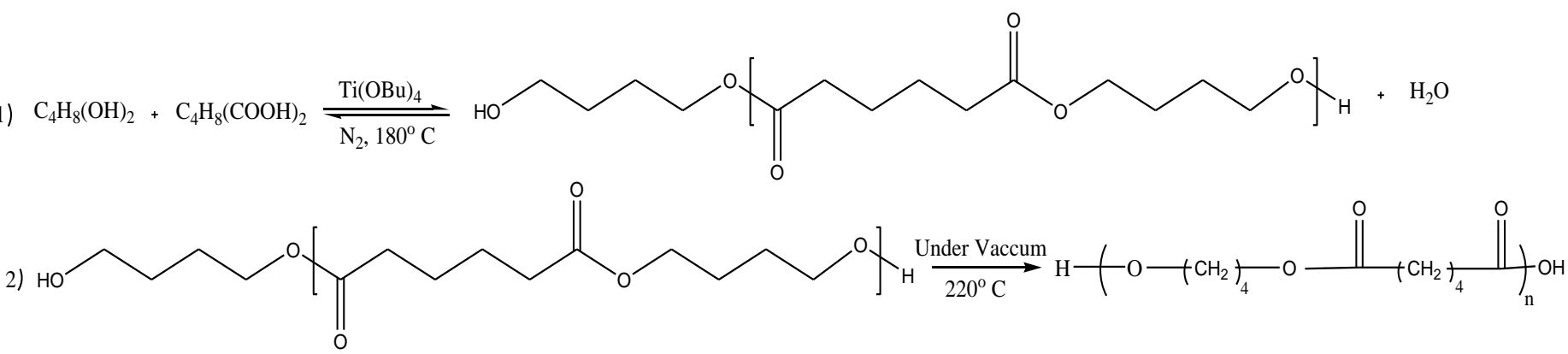

PBAT was also synthesized through three-stage melt polycondensation (two stages of esterification and then polycondensation) using BA, ADA, TA with TBT as catalyst (molar ration of 1:1:1:0.1, respectively). Nitrogen atmosphere and vigorous stirring were applied. The reaction is as follows:

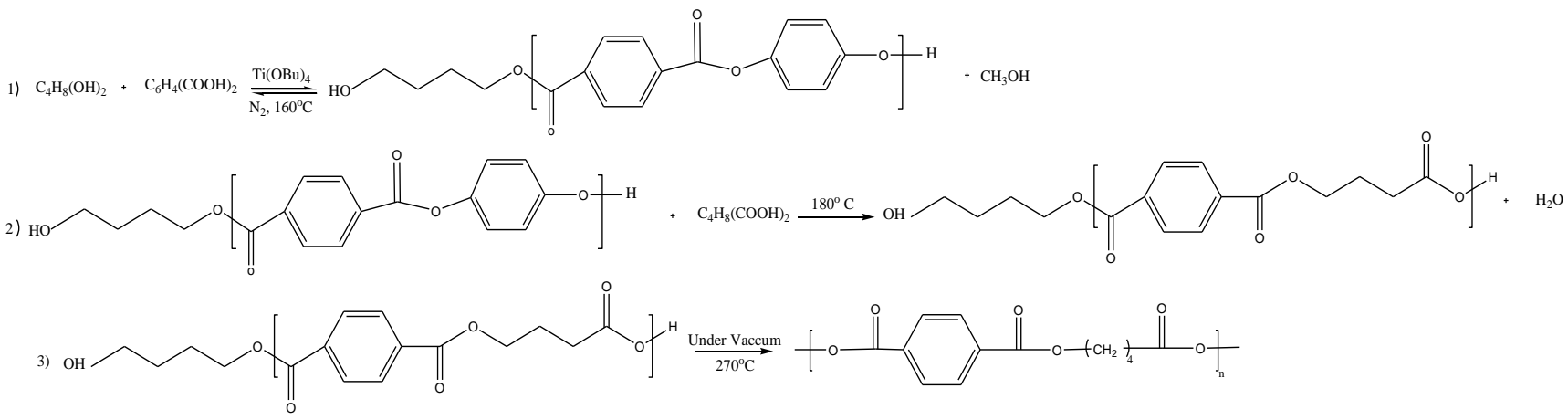

\subsubsection{BIO-NANOMAGNETITE SYNTHESIS}

Co-precipitation method was used based on similar previous works [28][29][30]. For first nanoparticle (PBAT), PBAT (dissolved in DMSO) were added to a round-bottom flask containing $\mathrm{Fe}_{2} \mathrm{Cl}_{3} .6 \mathrm{H}_{2} \mathrm{O}, \mathrm{Fe}_{\mathrm{Cl}} \mathrm{Cl}_{2}\left(\mathrm{molar}\right.$ ratio of $10^{-4}$ : 2:1, respectively), $\mathrm{HCl} 12 \mathrm{M}(0.85 \mathrm{ml})$ and distilled water $(25 \mathrm{ml})$. After partial dissolving, $\mathrm{NaOH} 1.5 \mathrm{M}(250 \mathrm{ml})$ was added drop wisely while stirring vigorously and nitrogen passing. When adding $\mathrm{NaOH}$ was completed, a black precipitation was obtained which was washed three times with distilled water and dried in vacuum oven for $24 \mathrm{~h}$ at $50^{\circ} \mathrm{C}$.

Another nanoparticle (PBA+PBAT) was also synthesized through the same procedure except that in addition to PBAT, PBA (dissolved in $\mathrm{CHCl}_{3}$ ) was also added (PBA:PBAT: $\mathrm{FeCl}_{3}: \mathrm{FeCl}_{2} \rightarrow$ 10-4: 10-4: 2:1). This precipitation was washed (three times) and dried at the same condition.

\subsubsection{SOLUTIONS OF PHTHALATES}

As nanoparticles are used to absorb phthalates from aqueous medium, first aqueous solution of them should be prepared. As they are insoluble in water, a 1000-ppm stock solution of each phthalate (dibutyl phthalate (DBPh) and dioctyl phthalate (DOPh) in methanol was prepared. Then, a 20-ppm solution was provided in methanol from 1000ppm stock solution of each one. Finally, 5-ppm aqueous solution was prepared from solutions of 20 ppm. These 5 ppm solutions were used for optimization process. 


\subsubsection{OPTIMIZATION PROCESS}

Optimization was performed for solution derived from absorption and desorption. First, weight of each nanoparticle was optimized for the absorption of each phthalate. Considered weights included $0.001 \mathrm{gr}, 0.005 \mathrm{gr}$, $0.01 \mathrm{gr}$, and $0.02 \mathrm{gr}$. Then, time intervals of $10 \mathrm{~min}, 20 \mathrm{~min}, 30 \mathrm{~min}, 45 \mathrm{~min}$, and $60 \mathrm{~min}$ was used for DBPh and 10 min, $20 \mathrm{~min}, 30 \mathrm{~min}, 45 \mathrm{~min}, 60 \mathrm{~min}$, and $75 \mathrm{~min}$ for DOPh. Finally, stirring speed was optimized for the absorption of each phthalate solution (250 rpm, $500 \mathrm{rpm}$, and $750 \mathrm{rpm}$ ).

Afterwards, desorption was optimized. First, volume of methanol was optimized (1.5 cc, $2 \mathrm{cc}, 2.5 \mathrm{cc}$ and $3 \mathrm{cc}$ ). Second, time intervals of $10 \mathrm{~min}, 30 \mathrm{~min}, 20 \mathrm{~min}$, and $40 \mathrm{~min}$ were considered. Finally, stirring speed was investigated (250 rpm, $500 \mathrm{rpm}$, and $750 \mathrm{rpm}$ ).

\section{RESULTS AND DISCUSSIONS}

\section{1. ${ }^{13}$ CNMR SPECTRA}

${ }^{13}$ CNMR spectra of polymers were taken (Browker, $400 \mathrm{MHz}$ ). Figs 1 and 2 show these spectra and their corresponding tables indicate their characterizing peaks.

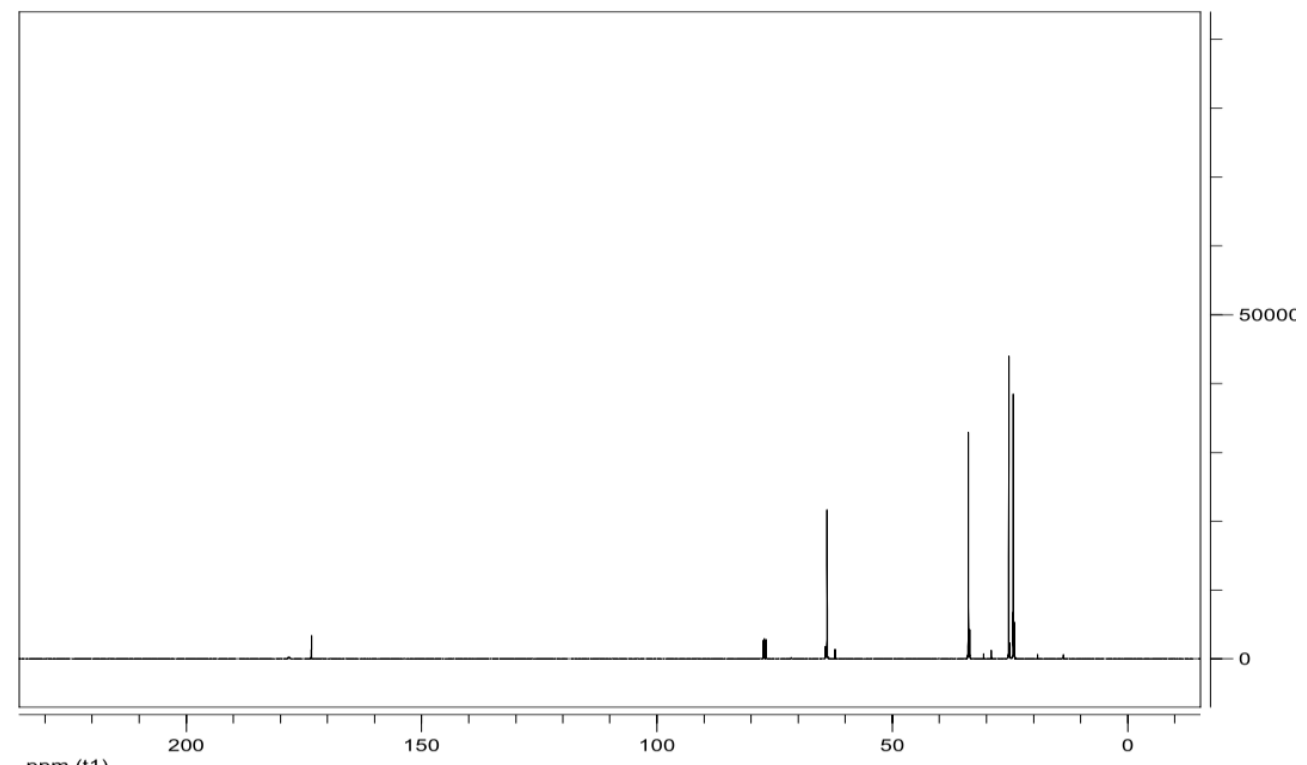

Figure 1: ${ }^{13} \mathrm{CNMR}$ spectrum of PBA<smiles>CC(C)O[13CH2]CCCOC(=O)CCCC[Te](=O)C(C)(C)O</smiles>

Table 1: Leading peaks of PBA ${ }^{13}$ CNMRspectrum

\begin{tabular}{|c|c|c|c|}
\hline Carbon type & Chemical shift $(\mathrm{ppm})$ & Carbon type & Chemical shift (ppm) \\
\hline f & 24.26 & $\mathrm{c}$ & 76.80 \\
\hline $\mathrm{b}$ & 25.24 & $\mathrm{~d}$ & 173.32 \\
\hline $\mathrm{e}$ & 33.80 & $\mathrm{~g}$ & 180 \\
\hline $\mathrm{a}$ & 63.80 & & \\
\hline
\end{tabular}




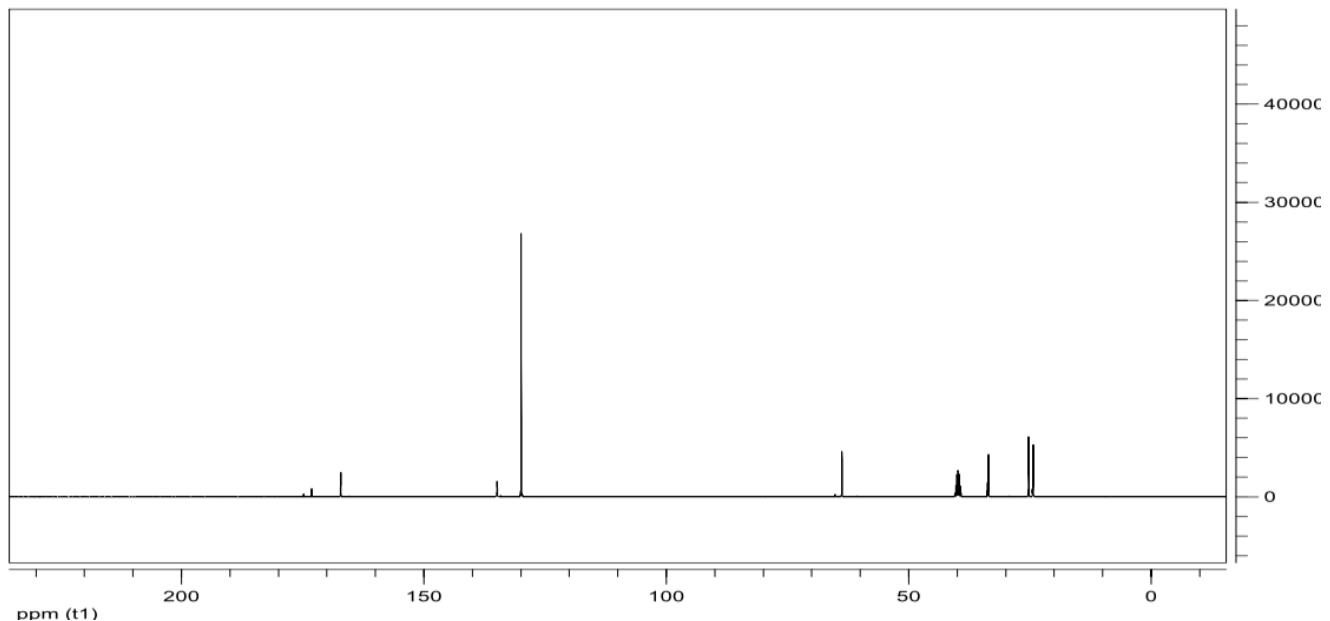

Figure 2: ${ }^{13} \mathrm{CNMR}$ spectrum of PBAT<smiles>CCCOC(=O)c1cpc(C(=O)OC(C)(C)C)pc1</smiles>

Table 2: Leading peaks of PBAT ${ }^{13}$ CNMR spectrum

\begin{tabular}{|c|c|c|c|}
\hline Carbon type & Chemical shift $(\mathrm{ppm})$ & Carbon type & Chemical shift (ppm) \\
\hline b & 129.88 & $\mathrm{e}$ & 25.29 \\
\hline c & 134.86 & $\mathrm{f}$ & 33.70 \\
\hline h & 176.09 & $\mathrm{~g}$ & 39.80 \\
\hline a & 173.09 & $\mathrm{~d}$ & 63.74 \\
\hline
\end{tabular}

\subsection{FTIR SPECTRUM}

Fourier Transform Infrared spectrum (FTIR) shows the characterizing peaks (Thermo Nicolet, AVATAR 370, USA). Fig. 3 shows the FTIR result of PBAT nanoparticles. Stretching Fe-0 peaks at $440.06 \mathrm{~cm}^{-1}$ and $601.11 \mathrm{~cm}^{-1}$, OOP peaks of para substituents at $877.35 \mathrm{~cm}^{-1}$, aromatic stretching $\mathrm{C}=\mathrm{C}$ at the range of $1475-1630 \mathrm{~cm}^{-1}, \mathrm{C}-0$ stretching peaks at $1000-1300 \mathrm{~cm}^{-1}$ and broad peak at about $3395 \mathrm{~cm}^{-1}$ for stretching $0-\mathrm{H}$ are observed which confirmed polymer coating structure. Peaks at 1008.2 and 629.31 can be of esteric characteristic peaks but they are shifted backward due to Fe bounding.

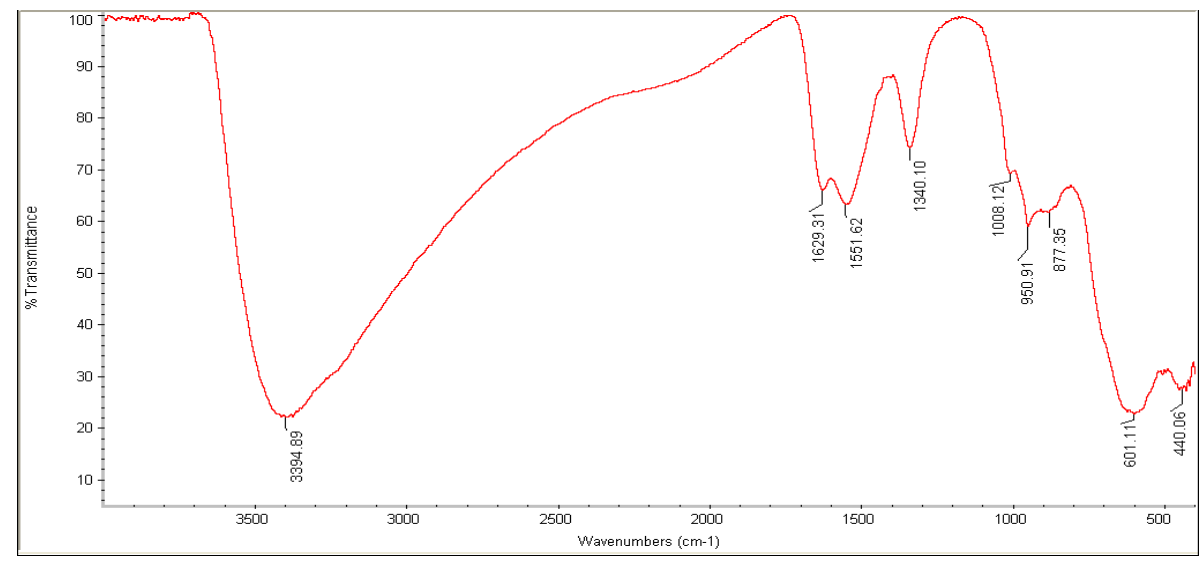

Figure 3: FTIR spectrum of PBAT nanoparticles 
Also FTIR spectrum of PBA+PBAT nanoparticles is shown in Fig. 4 which disclosed characteristic peaks of stretching Fe-O (432.69 $\mathrm{cm}^{-1}$ and $\left.588.24 \mathrm{~cm}^{-1}\right)$, C-H chain bending $\left(1413.39 \mathrm{~cm}^{-1}\right.$.), and $\mathrm{O}-\mathrm{H}$ stretching band (3373.06 $\mathrm{cm}^{-1}$ ). Peaks at 1634.05 and 1020.21 can point to ester characteristics peaks but they are shifted backwards which can be due to the iron bounding with the oxygen atom of esoteric group.

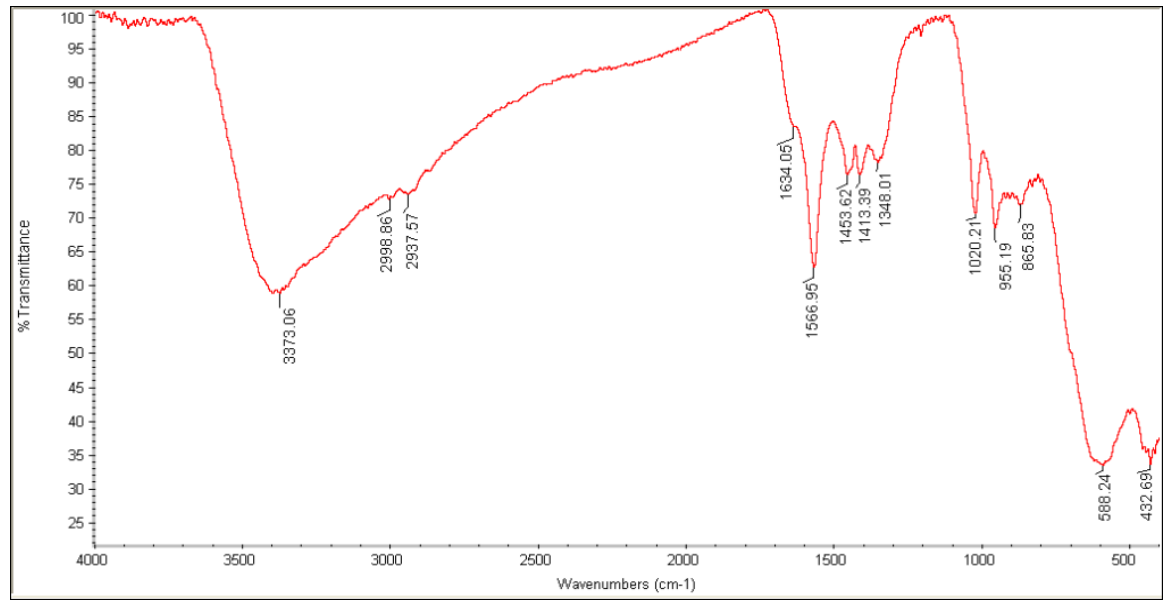

Figure 4: FTIR spectrum of PBA+PBAT nanoparticles

\subsection{XRD TEST}

Results of X-ray diffraction spectrum can be observed in Fig. 5. This test was performed from $20^{\circ}$ to $80^{\circ}$ and $\mathrm{CuK} \alpha$ was used. According to this spectrum, crystalline structure of iron is maintained after coating as characteristic peaks of iron can be recognized in the spectrum. In addition, relative size of the particles based on Debye-Scherrer relation was obtained $(9.12 \mathrm{~nm})$.

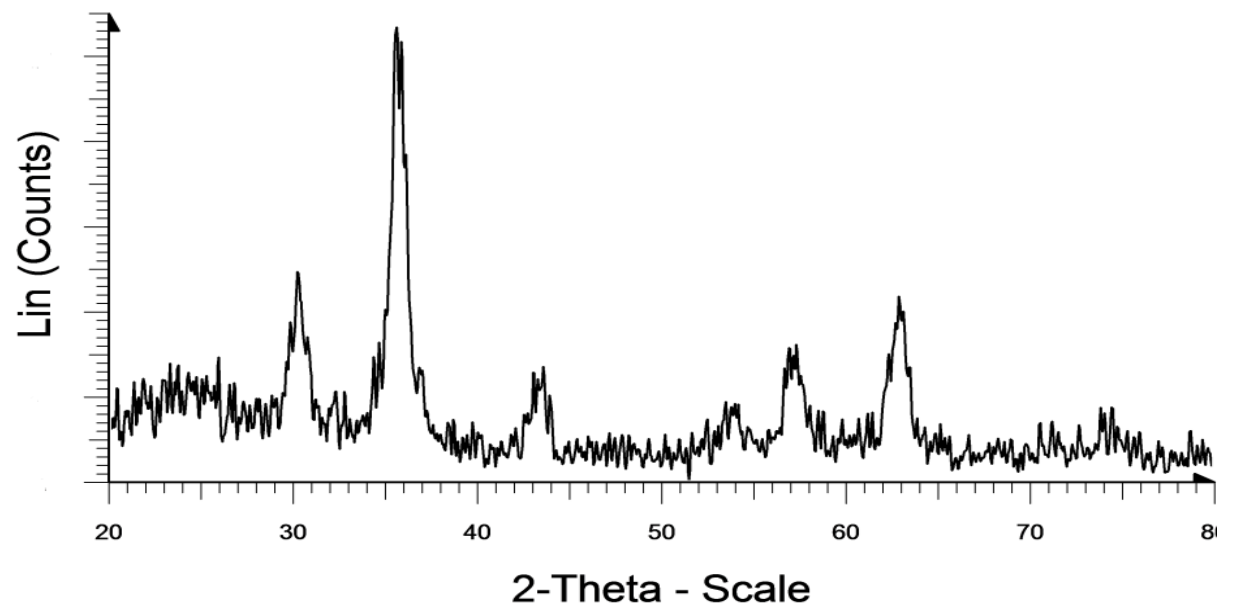

Figure 5: XRD spectrum of nanoparticle

\subsection{OPTIMIZATION}

First, wavelength for phthalates absorption should be determined. So, 20-ppm methanol solutions of both DBPh and DOPh were obtained with UV-Vis spectroscopy. It was found that the wavelength was $247 \mathrm{~nm}$. To determine whether the nanoparticles had the capacity to absorb phthalates, aqueous solutions of dibutyl phthalate were obtained and PBAT and PBAT+PBA nanoparticles were added. Then, UV spectrum of desorption was taken while methanol was considered as blank. Results are as follows. 


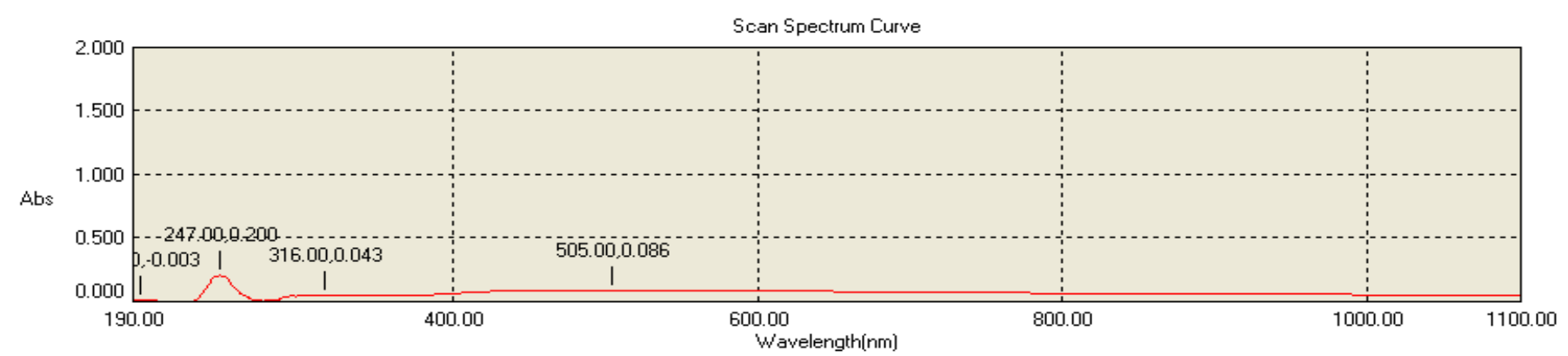

Figure 6: Desorption of DBPh by PBAT nanoparticles

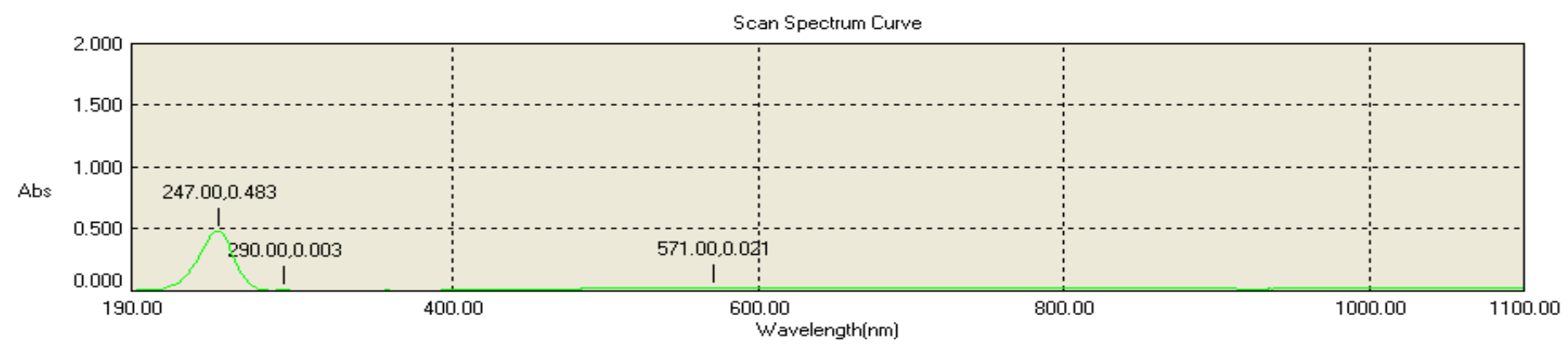

Figure 7: Desorption of DBPh by PBAT+PBA nanoparticles

As it was mentioned that time, nanoparticle weight and stirring speed were optimized for absorption of $\mathrm{DBPh}$ and DOPh from aqueous solution.

Optimum desorption conditions were also obtained. Nanoparticles obtained from optimum absorption were put in methanol and then UV-Vis spectrum was taken. Volume, time and stirring speed were optimized and results are given in table 3.

Table 3: Optimum conditions for absorption and desorption of phthalates by bio-nanoparticles

\begin{tabular}{|c|c|c|c|c|c|c|}
\hline \multicolumn{7}{|c|}{ Absorption } \\
\hline \multirow[t]{2}{*}{ Material } & \multicolumn{3}{|c|}{ PBAT nanoparticles } & \multicolumn{3}{|c|}{ PBAT+PBAT nanoparticles } \\
\hline & Weight (gr) & Time (min) & Stirring speed (rpm) & Weight (gr) & Time (min) & Stirring speed (rpm) \\
\hline $\mathrm{DBPh}$ & 0.01 & 20 & 500 & 0.01 & 45 & 500 \\
\hline DOPh & 0.005 & 30 & 500 & 0.005 & 60 & 500 \\
\hline \multicolumn{7}{|c|}{ Desorption } \\
\hline \multirow[t]{2}{*}{ Material } & \multicolumn{3}{|c|}{ PBAT nanoparticles } & \multicolumn{3}{|c|}{ PBAT+PBAT nanoparticles } \\
\hline & Volume (ml) & Time (min) & Stirring speed (rpm) & Volume (ml) & Time (min) & Stirring speed (rpm) \\
\hline DBPh & 2.5 & 30 & 500 & 2.5 & 20 & 500 \\
\hline DOPh & 2.5 & 30 & 500 & 2.5 & 20 & 500 \\
\hline
\end{tabular}

\subsection{CALIBRATION}

Generally, calibration is a kind of operation in which an output quantity is related to an input quantity for a measuring system under given conditions (IUPAC). Linear regression is used to determine the equation which best explains the linear relationship between the response (y) and analyte level (x) (in this work, $y$ is the absorbance level and $\mathrm{x}$ is the concentration). This relation is described by the equation of the line, i.e., $\mathrm{y}=\mathrm{mx}+\mathrm{c}$ in which $\mathrm{m}$ is the gradient of the line and $c$ is the intercept with the $y$-axis. The correlation coefficient, $r$ (and the related parameter $r^{2}$ ) shows the strength of correlation between the $y$ and $x$ values. It can take any value from +1 to -1 and the closer it is to 1 , the stronger the correlation. This correlation coefficient is commonly used in analytical measurement. The 
Synthesis of Bio-Nanomagnetite and Its Optimized Conditions for Phthalate Absorption

particular value of $\mathrm{r}$ can indicate a statistically significant correlation between $\mathrm{y}$ and $\mathrm{x}$ depends on the number of data points used to calculate it (calibration curve guide).

In order to plot calibration graphs, different aqueous concentrations of DBPh and DOPh were prepared $(0.01$ ppm, $0.05 \mathrm{ppm}, 0.1 \mathrm{ppm}, 0.5 \mathrm{ppm}, 1 \mathrm{ppm}, 5 \mathrm{ppm}, 10 \mathrm{ppm}$, and $15 \mathrm{ppm}$ ) and then, nanoparticles were added. In each case, four or five suitable points were selected to plot the graphs. Results are shown in the following Figs (8-11).

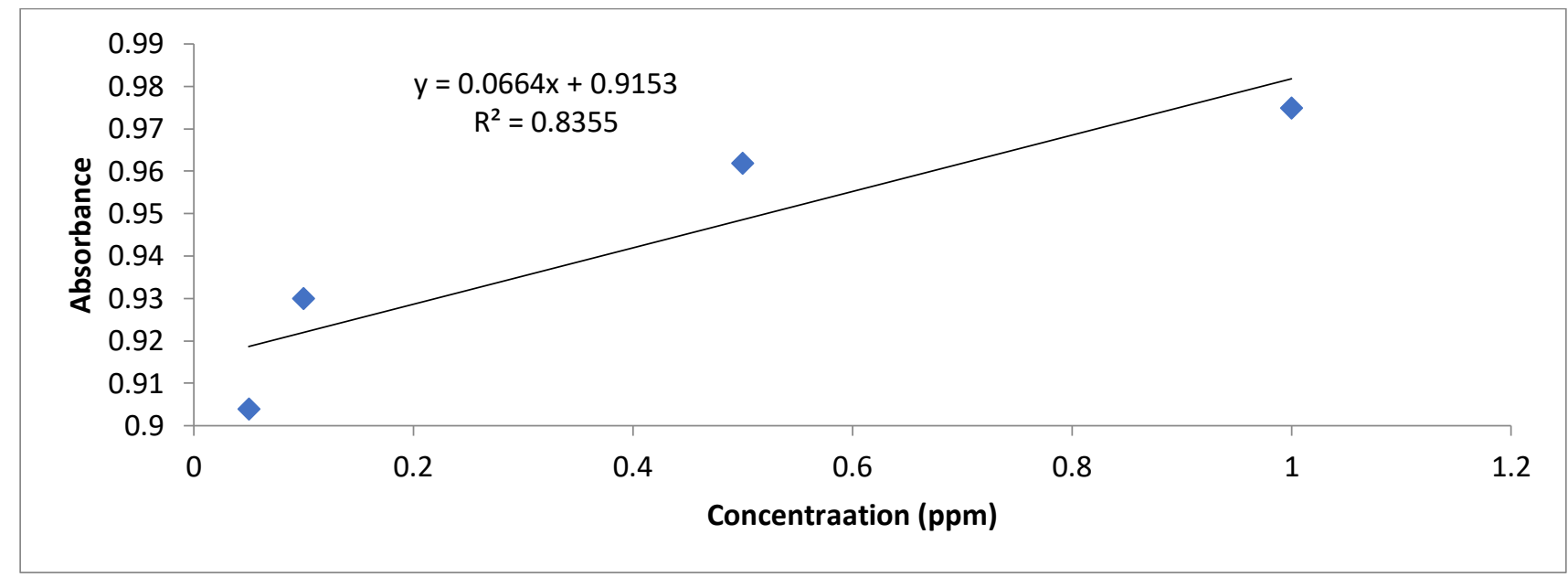

Figure 8: Calibration graph of DBPh desorption from PBAT nanoparticles

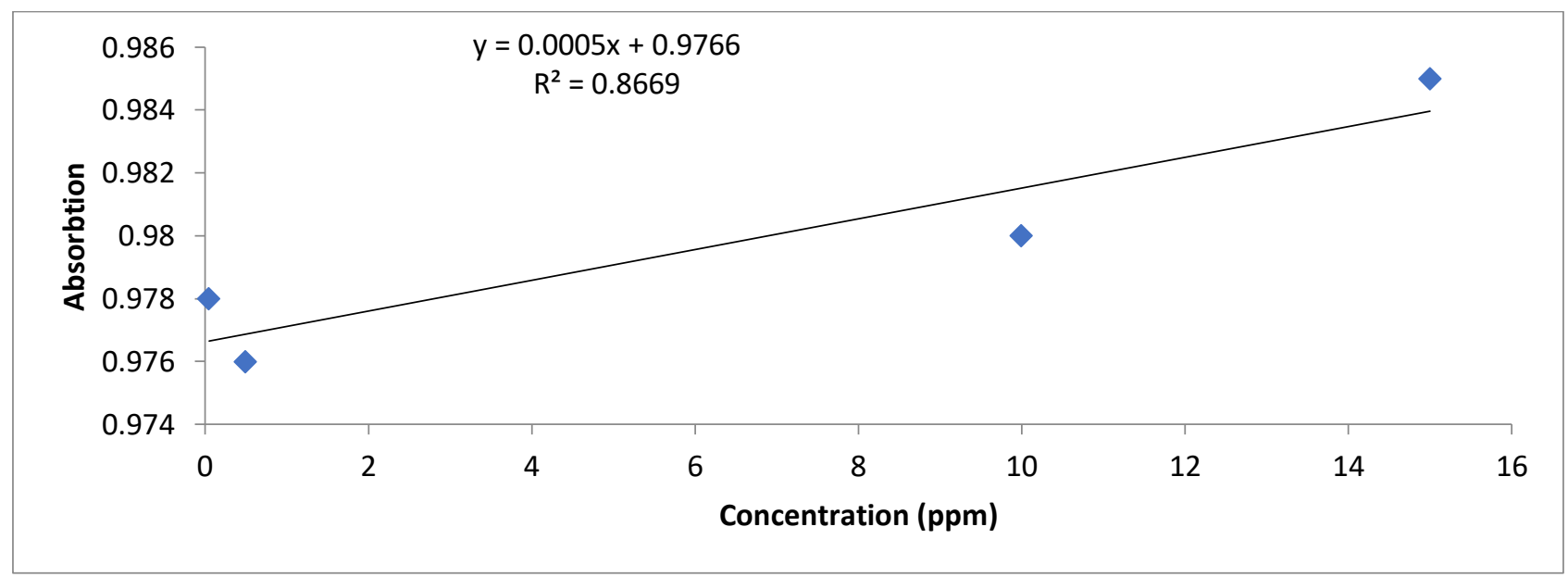

Figure 9: Calibration graph of DBPh desorption from PBA+PBAT nanoparticles

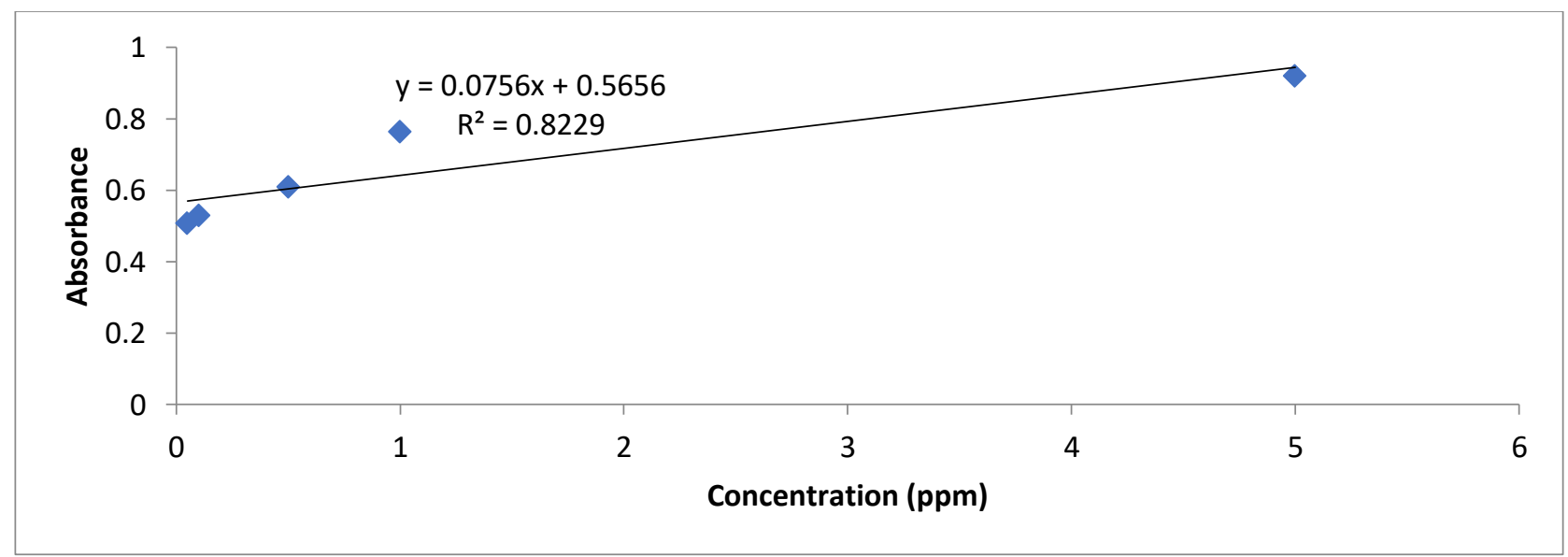

Figure 10: Calibration graph of DOPh desorption from PBAT nanoparticles 


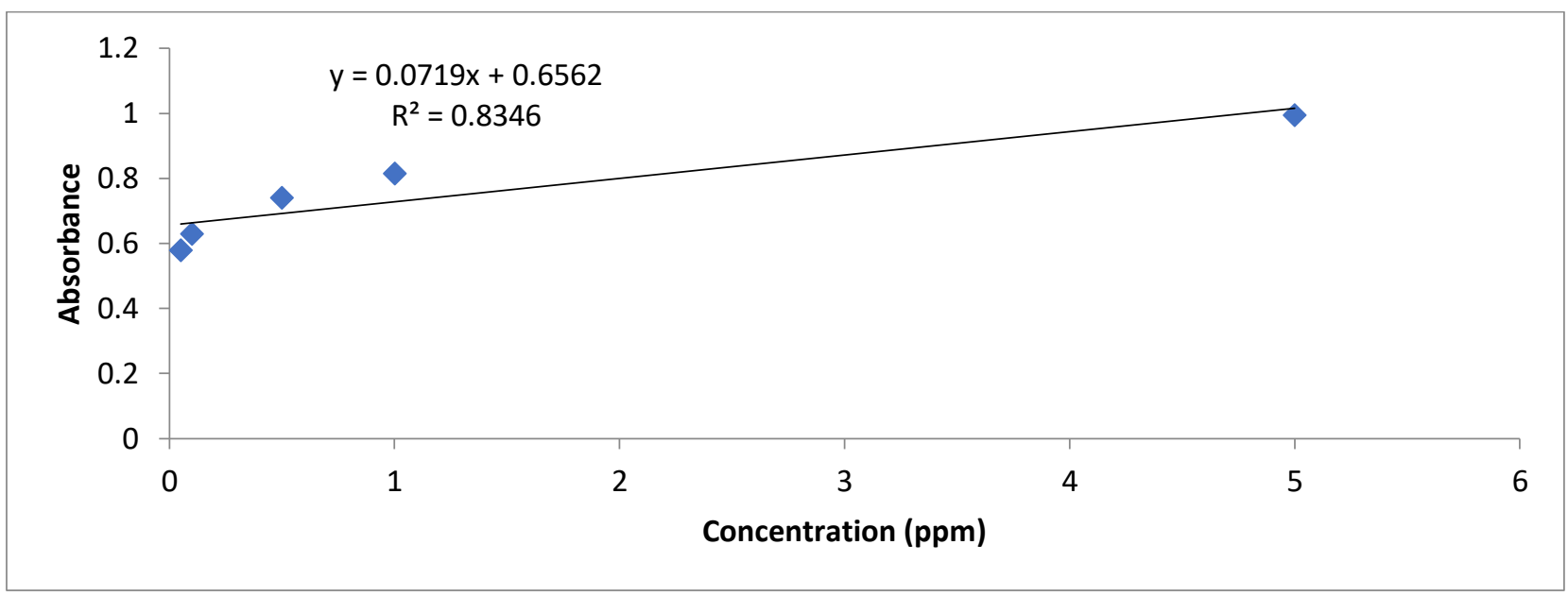

Figure 11: Calibration graph of DOPh desorption from PBA+PBAT nanoparticles

As it can be seen from the Figs, there seems to be good correlations between absorbance and concentration (values of $\mathrm{R}^{2}$ are close to one). In each case, the equation may be used to estimate the amount of absorbance in any concentration. There are some fluctuations in absorbance amount of different concentrations which can be attributed to the instrument error tolerance and slight differences during preparing different concentrations of the stock solution.

\subsection{ISOTHERMS}

Isotherms were also plotted for these solutions at five different temperatures $\left(15^{\circ}, 20^{\circ}, 25^{\circ}, 30^{\circ}\right.$ and $\left.35^{\circ} \mathrm{C}\right)$. Four prepared isotherms are illustrated below.

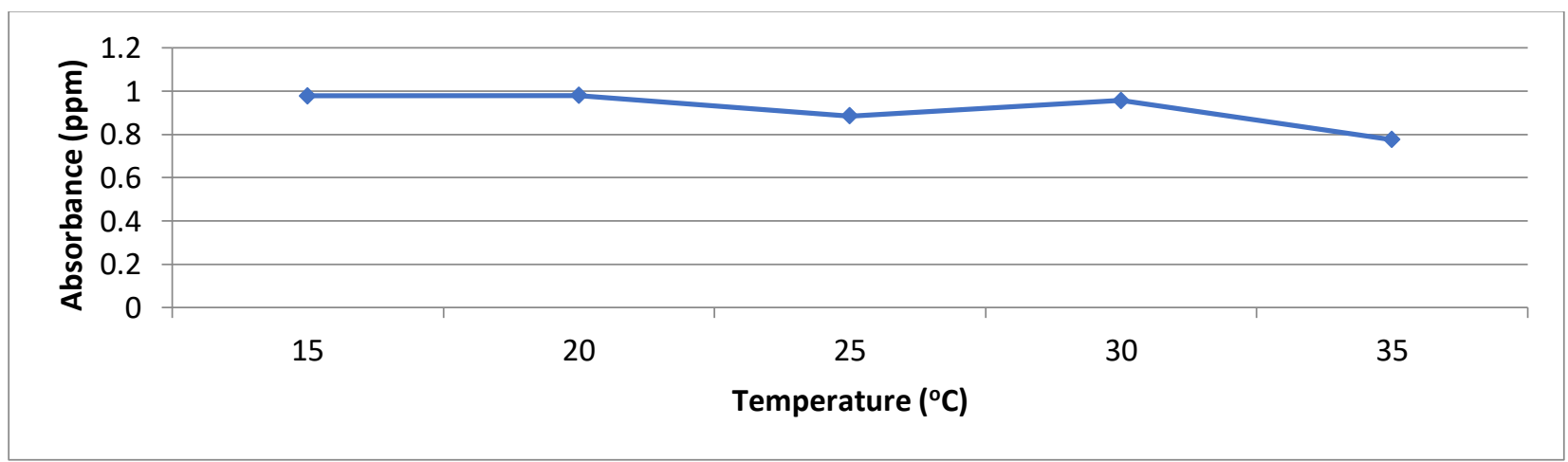

Figure 12: Isotherm of DBPh absorbance by PBAT nanoparticles in different temperatures

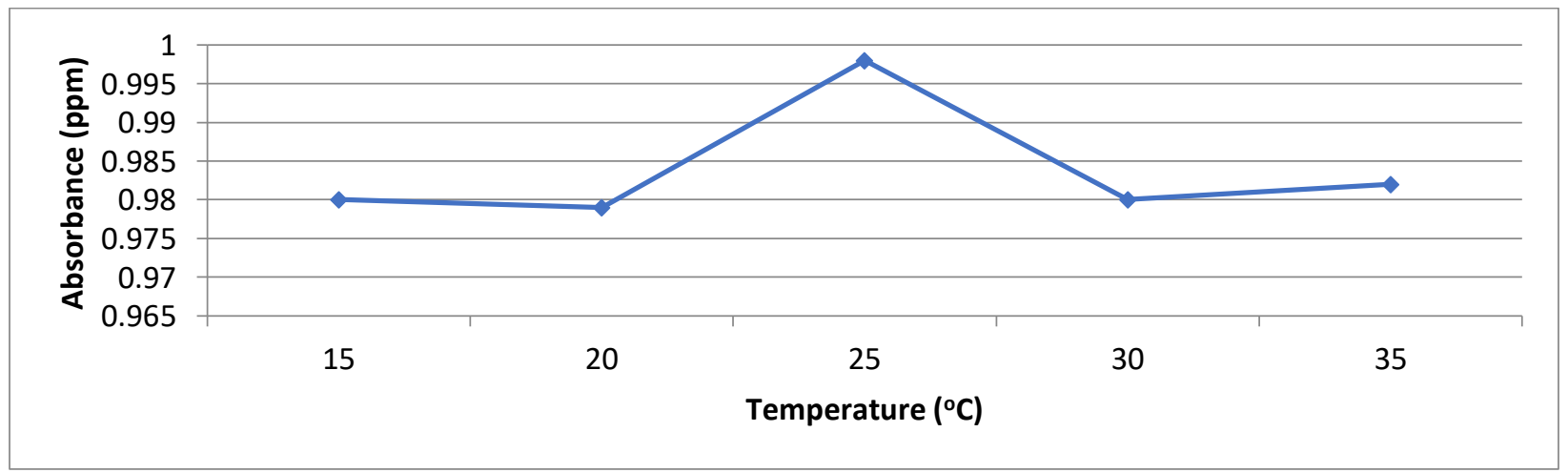

Figure 13: Isotherm of DBPh absorbance by PBA+PBAT nanoparticles in different temperatures 
Synthesis of Bio-Nanomagnetite and Its Optimized Conditions for Phthalate Absorption

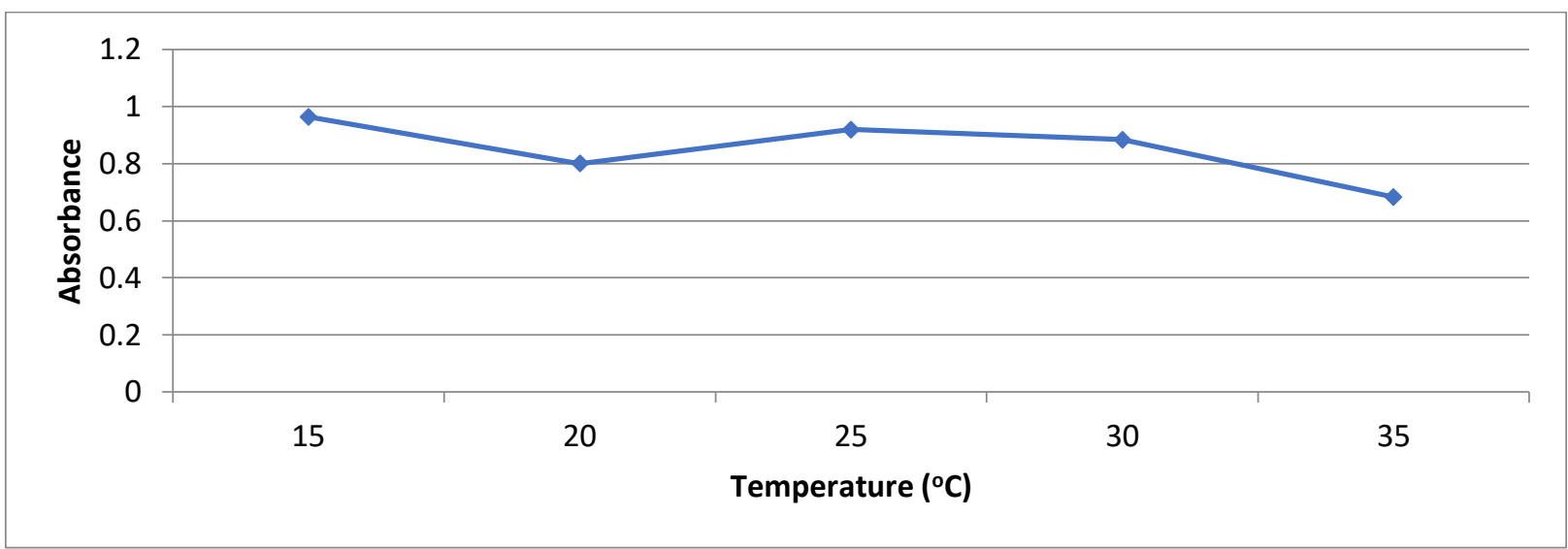

Figure 14: Isotherm of DOPh absorbance by PBAT nanoparticles in different temperatures

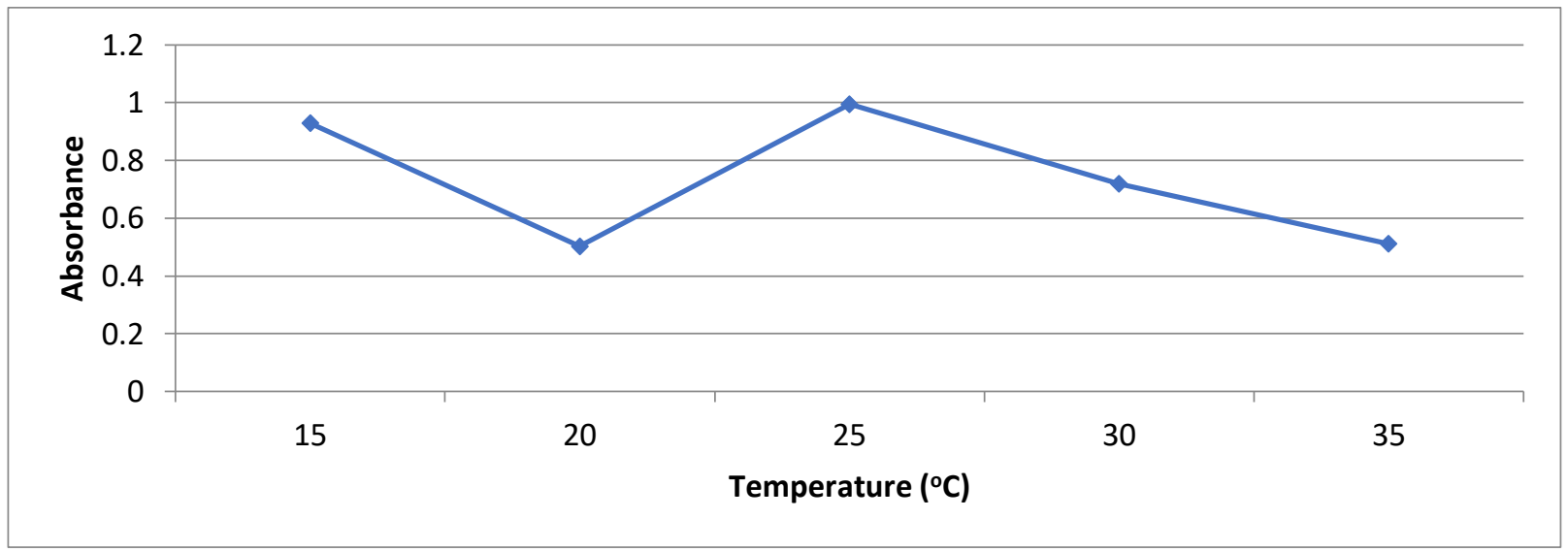

Figure 15: Isotherm of DOPh absorbance by PBA+PBAT nanoparticles in different temperatures

\section{CONCLUSIONS}

Bio-nanomagnetite particles were synthesized in this work. First, two biodegradable polymers of PBA and PBAT were produced using two- and three-stage melt polycondensation. Their characteristics were studied using ${ }^{13} \mathrm{CNMR}$ spectra. Next, two different bio-nanomagnetites were synthesized using $\mathrm{FeCl}_{3}$ and $\mathrm{FeCl}_{2}$ through co-precipitation method. Nanomagnetite particles were coated with PBAT and PBA + PBAT. FTIR and XRD spectra of bionanomagnetites were obtained. These coated particles were used to absorb DOPh and DBPh from aqueous medium and their performance were optimized regarding particle weight, absorption and desorption duration, volume of desorption solvent, and stirring speed.

Findings show that PBA+PBAT NP was better in absorbing phthalates from aqueous solution that PBAT NP which may be because combined NP has more functional group and reaction site on its surface than PBAT NP. ${ }^{13} \mathrm{CNMR}$ spectra show peaks may be assigned to functional groups of the polymers. In addition, FTIR spectra of bionanoparticles illustrate peaks related to both polymers and iron salts. X-ray diffraction spectrum indicates the relative size of the particles based on Debye-Scherrer relation $(9.12 \mathrm{~nm})$. Calibration graphs show a good correlation between absorbance and concentration with values of $\mathrm{R}^{2}$ approaching one. Optimum features were also obtained and summarized in table 3.

These nanoparticles can be used to absorb phthalates from aqueous solution under optimized conditions which multiplies their efficiency. They are biodegradable and also reusable. Therefore, they can be used with the least trace on the environment. 


\section{SOURCES OF FUNDING}

None.

\section{CONFLICT OF INTEREST}

None.

\section{ACKNOWLEDGMENT}

Hereby the author thanks Dr. H. Atashin for helping in analyzing XRD tests and supporting this work.

\section{REFERENCES}

[1] Terris BD, Thomson T. Nanofabricated and self-assembled magnetic structures as data storage media. Journal of Applied Physics. 2005;38:199-222.

[2] Sahoo Y, Goodarzi A, Swihart MT, Ohulchanskyy TY, Kaur N, Furlani EP, and Prasad PN. Aqueous Ferrofluid of Magnetite Nanoparticles: Fluorescence Labeling and Magnetophoretic Control. Journal of Physical Chemistry. 2005;109:3879-3885.

[3] Cunningham CH, Arai T, Yang PC, McConnell MV, Pauly JM, and Conolly SM. Positive contrast magnetic resonance imaging of cells labelled with magnetic nanoparticles. Magnetic Resonance in Medicine. 2005;53:999-1005.

[4] Dobson J. Magnetic nanoparticles for drug delivery. Drug Development Research. 2006;67:55-60.

[5] Safarik I, and Safarikova M. Magnetic techniques for the isolation and purification of proteins and peptides. BioMagnetic Research and Technology. 2004;2:1-17.

[6] Carlos L, Garcia Einschlag FS, Gonzalez MC, and Martire DO. Waste Water - Treatment Technologies and Recent Analytical Developments. In: Applications of magnetite nanoparticles for heavy metal removal from wastewater. INTECH. 2013;63-77.

[7] Zhang J and Misra RDK. Magnetic drug-targeting carrier encapsulated with thermosensitive smart polymer: core-shell nanoparticle carrier and drug release response. Acta Biomaterialia. 2007;3:838-850. https//: 10.1016/j.actbio.2007.05.011

[8] Matsura V, Guari Y, Larionova J, Guerin C, Caneschi A, Sangregorio C, Lancelle-Beltran E, Mehdi A and Corriu RJP. Synthesis of magnetite silica-based nanocomposites containing $\mathrm{Fe}_{3} \mathrm{O}_{4}$ nanoparticles. The Royal Society of Chemistry. 2004:14;3026-3033. https//:10.1039/B409449B

[9] Hung YP. Encapsulation of nanomagnetite within polycaprolactone microsphere for bone replacement. In: Introduction. School of Chemical Engineering, University of Birmingham. 2011; 1-3.

[10] Gupta AK and Gupta M. Synthesis and surface engineering of iron oxide nanoparticles for biomaterial applications. Biomaterials. 2005;26:3995-4021. https//:10.1016/j.biomaterials.2004.10.012

[11] Blaney L. Magnetite $\left(\mathrm{Fe}_{3} \mathrm{O}_{4}\right)$ : properties, synthesis, and applications. Lehigh Review. 2007;15:33-81.

[12] Maity D, and Agrawal DC. Synthesis of iron oxide nanoparticles under oxidizingenvironment and their stabilization in aqueous and non-aqueous media. Journal of Magnetism and Magnetic Materials. 2007;308:46-55.

[13] Chen S, Xu Z, Dai H, and Zhang S. Facile synthesis and magnetic properties of monodisperse $\mathrm{Fe}_{3} \mathrm{O}_{4} / \mathrm{silica}$ nanocomposite microspheres with embedded structures via a direct solution-based route. Journal of Alloys and Compounds. 2010;497:221-227.

[14] Gupta AK, and Gupta M. Synthesis and surface engineering of iron oxide nanoparticles for biomedical applications. Biomaterials. 2005;26:3995-4021. 
Synthesis of Bio-Nanomagnetite and Its Optimized Conditions for Phthalate Absorption

[15] Chomoucka J et al. Cell toxicity and preparation of streptavidin-modified iron nanoparticles and glutathionemodified cadmium-based quantum dots. Procedia Engineering, 2010;5:922-925.

[16] Enzel P, Adelman N, Beckman KJ, Campbell DJ, Ellis AB, and Lisensky GC (1999). Preparation of an aqueous-based ferrofluid. Journal of Chemical Education. 1999;76:943-948.

[17] Lee S Y, and Harris MT. Surface modification of magnetic nanoparticles capped by oleic acids: characterization and colloidal stability in polar solvents. Journal of Colloid and Interface Science. 2006;293:401-408.

[18] W Yantasee, Warner CL, Sangvanich T, Addleman RS, Carter TG, Wiacek RJ, Fryxell GE, Timchalk C, and Warner MG. Removal of heavy metals from aqueous systems with thiol functionalized superparamagnetic nanoparticles. Environmental Science and Technology. 2007;41:5114-5119.

[19] Zhang M, Pan G, Zhao D and He G. XAFS study of starch-stabilized magnetite nanoparticles and surface speciation of arsenate. Environmental Pollution. 2011;159: 3509-3514.

[20] Lee J, Isobe T, Senna M. Preparation of ultrafine $\mathrm{Fe}_{3} \mathrm{O}_{4}$ particles by precipitation in the presence of PVA at high pH. Journal of Colloid and Interface Science. 1996:177;490-494.

[21] Zinali S, Sabbaghi S, Nasirimoghaddam S. Chitosan coated magnetic nanoparticles as nano-adsorbent for efficient removal of mercury contents from aqueous and oily samples. Proceedings of the $4^{\text {th }}$ International Conference on Nanostructures (ICNS4). 2012:1482-1484.

[22] Baghayeri M, Zare EN, Lakouraj MM. Novel superparamagnetic $\mathrm{PFu@} \mathrm{Fe}_{3} \mathrm{O}_{4}$ conductive nanocomposite as a suitable host for hemoglobin immobilization. Sensors and Actuators B: Chemical. 2014: 202;1200-1208.

[23] Jiang H, Chen P, Luo S, Luo X, Tu X, Cao Q, Zhou Y, Zhang W. Synthesis of novel biocompatible composite $\mathrm{Fe}_{3} \mathrm{O}_{4} / \mathrm{ZrO}_{2} /$ chitosan and its application for dye removal. Journal of Inorganic Organometal Polymer Materials. 2013:23;393-400.

[24] Tienpont B, David F, Dewull E, and Sandra P. itfalls and Solutions for the Trace Determination of Phthalates in Water Samples. Chromatographia. 2005:61;365-370.

[25] Sablayrolles C, Montrejaud-Vignoles M, Benanou D, Patria L, and Treilhou M. Development and validation of methods for the trace determination of phthalates in sludge and vegetables. Journal of chromatographer. 2005:1072;223-242

[26] Zalieckaite R, Adomaviciute E, and Vickackaite V. Single-drop microextraction for the determination of phthalate esters. Chemical Journal A. 2007:18; 25-29.

[27] Massoudi AH, Hosseini F, and Maghsoodi S. Synthesis of Biodegradable Poly (butylene adipate) and CoPolymer of Poly (butylene adipate-co-terephthalate) and Comparing their Characteristics. Journal of Harmonized Research in Applied Science. 2015:3(unpublished)

[28] Kandpla N, Sah DM, Loshali N, Joshi R, and Prasad J. Co-precipitation method of synthesis and characterization of iron oxide nanoparticles. Journal of scientific and industrial research. 2013:73;87-90.

[29] Businova P, Chomoucka J, Prasek J, Drbohlavova J, Sedlacek P, and Hubalek J. Polymer-coated iron oxide magnetic nanoparticles- preparation and characterization. Nanoconference. 2011

[30] Shen YF, Tang J, Nie ZH, Wang YD, Ren Y, and Zuo L. Preparation and application of magnetic $\mathrm{Fe}_{3} \mathrm{O}_{4}$ nanoparticles for wastewater purification. Separation and purification technology. 2009:68;312-319. 